\title{
Surface Analysis of Titanium Dental Implants with Different
}

\section{Topographies}

M.H. Prado da Silva ${ }^{\mathrm{a}}$, G.A. Soares ${ }^{\mathrm{a}}{ }^{*}$, C.N. Elias 
authors $^{5-7}$. There are two main mechanisms of bone-implant attachment: mechanical attachment and chemical attachment. Roughness mainly improves mechanical attachment as it permits bone to grow through pores or features on the surface of the implant. On the other hand, the contribution of roughness to the improvement of osseointegration is not only mechanical. Features like surface tension and thus surface energy, can change the hydrophobic character of a surface. The ability a surface has to adsorb organic molecules like proteins is directly related to biocompatibility. In this context, surface roughness has been found to positively influence cell response to titanium implants ${ }^{8-10}$. Some authors have also investigated the influence of surface roughness on bone attachment and concluded that rougher surfaces result in improved tissue responses to titanium implants ${ }^{6,11-13}$.

In this study, four different types of surfaces were produced on titanium implants and these were characterised by SEM, LSM, XPS and optical laser profilometry. The surface conditions were: as-machined; blasted with alumina particles; plasma sprayed with titanium beads and electrolytically coated with hydroxyapatite (HA). The HA coating procedure was developed by Silva and co-workers 14 

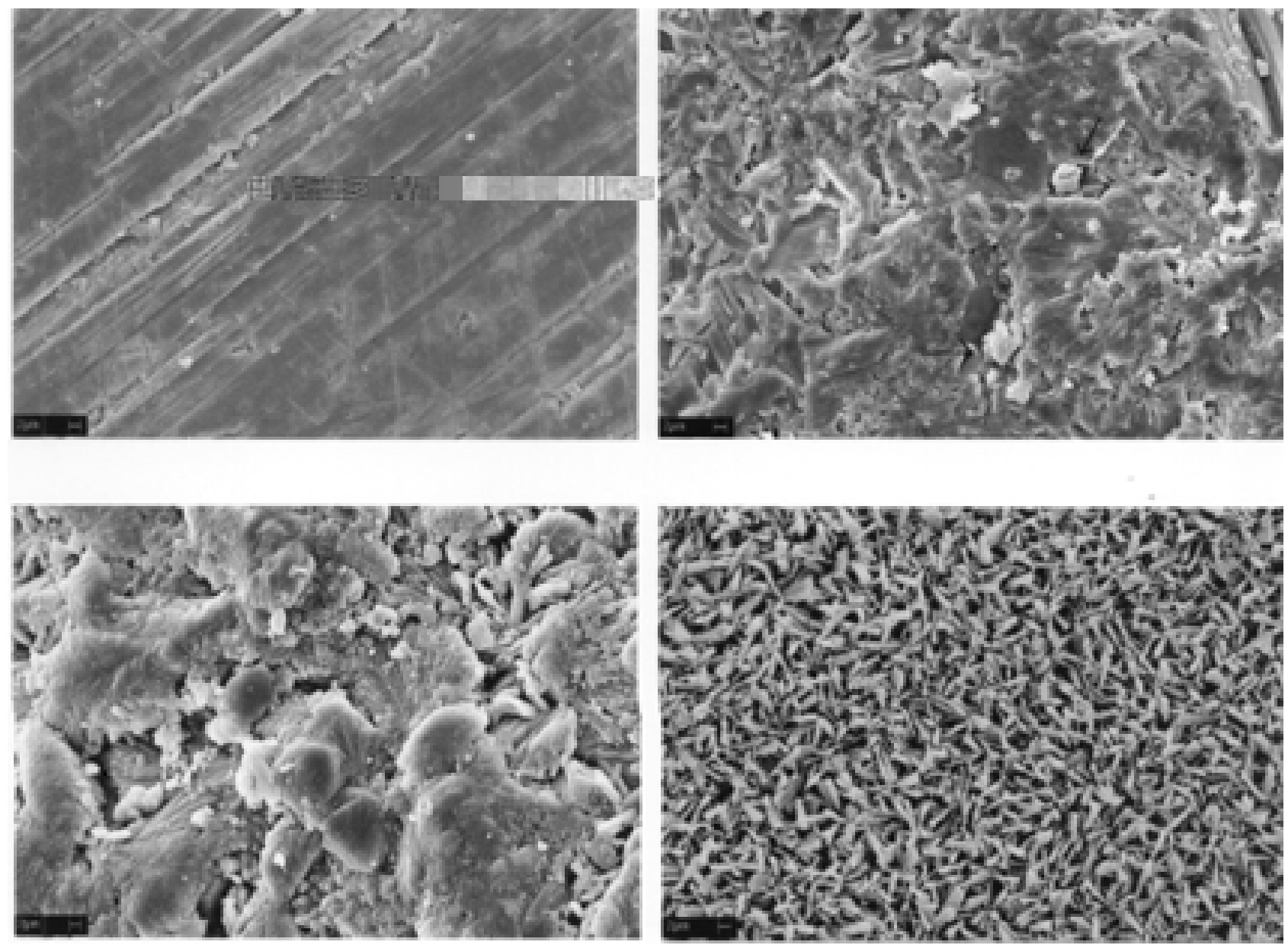

Figure 1. SEM picture showing the surface of the implant: (x 3.000). a) as-machined; b) $\mathrm{Al}_{2} \mathrm{O}_{3}$ blasted; c) plasma-sprayed with titanium; d) electrolitically coated with hydroxyapatite.

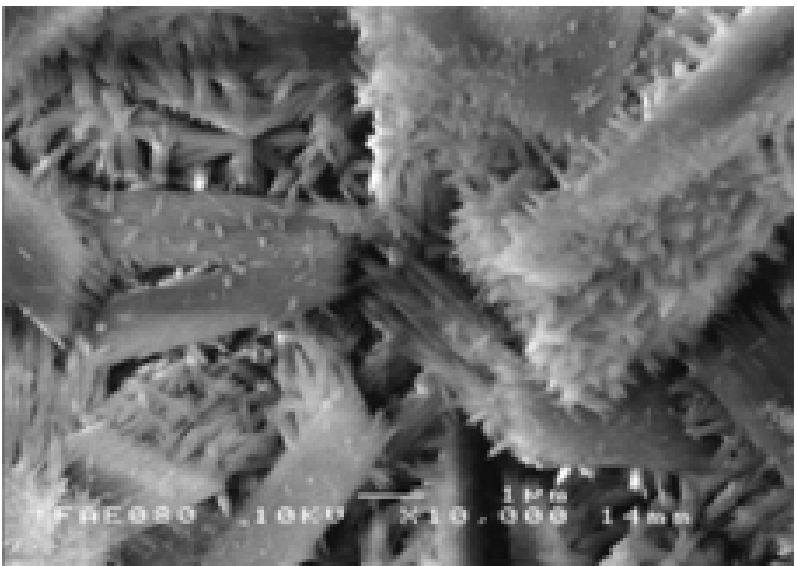

Figure 2. Hydroxyapatite coated implant under high magnification. (x 10.000).

process as, usually, adhesive strength increases with decreasing coating thickness ${ }^{17}$. Willmann ${ }^{17}$ explains the compromise between coating thickness and adhesion in terms of the tendency thicker coatings have to peel off their substrates. The ideal value for coating thickness has not

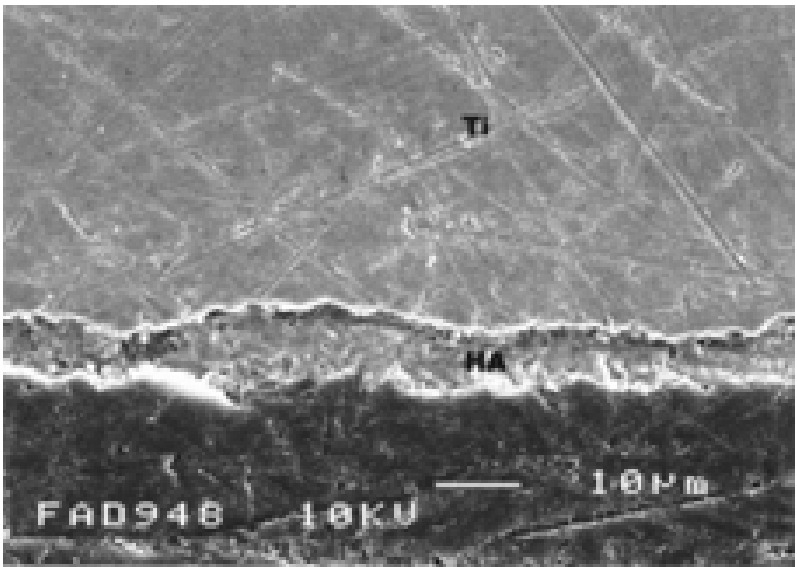

Figure 3. Cross section the specimen electrolytically coated with hydroxyapatite (x 1.000).

already been determined because there is a compromise between thickness and resorption and it is not well established how long a coating needs to be present after insertion in the human body ${ }^{18}$. 

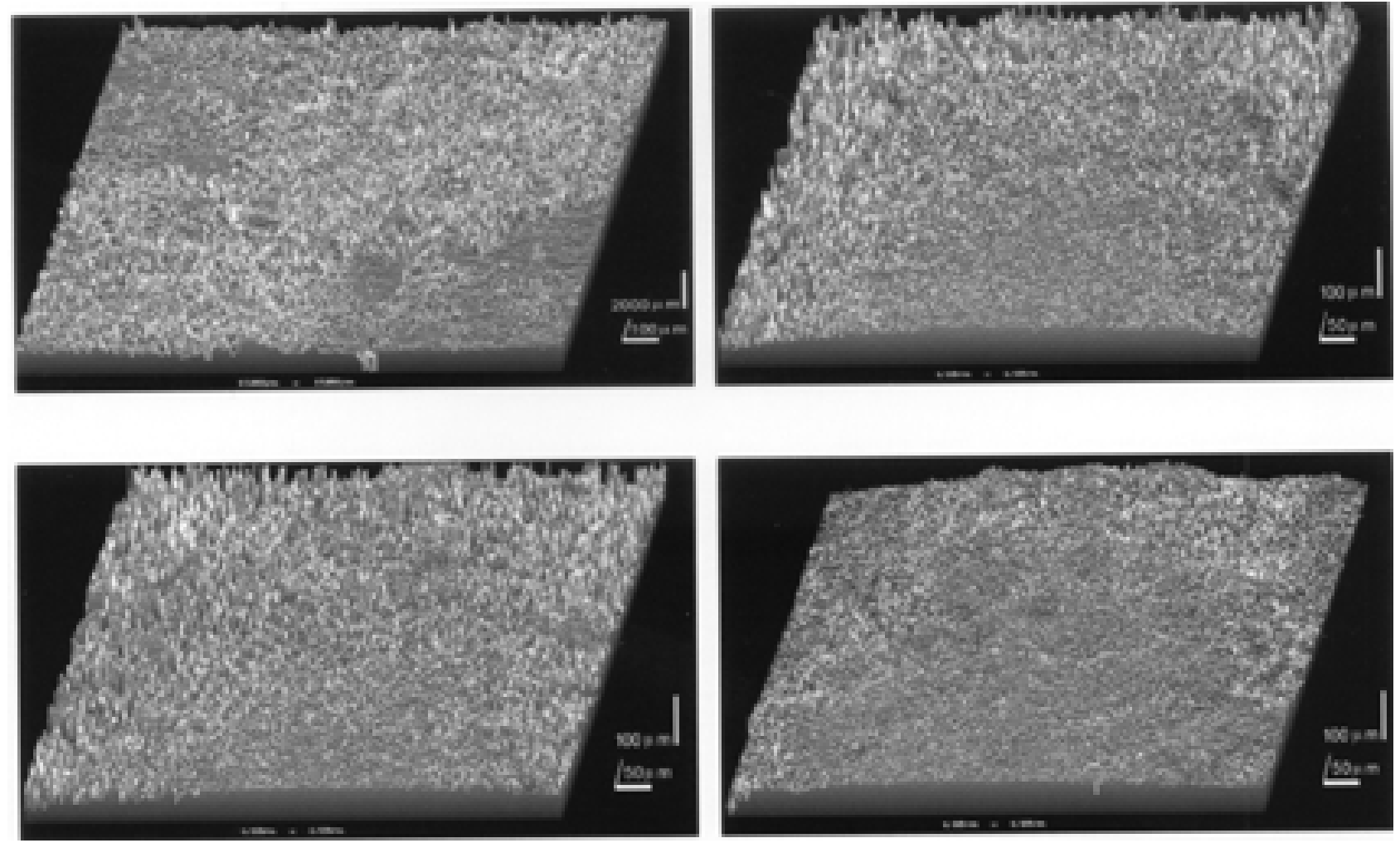

Figure 4. Topography maps for the specimens: a) as-machined; b) $\mathrm{Al}_{2} \mathrm{O}_{3}$ blasted; c) plasma-sprayed with titanium; d) electrolytically coated with hydroxyapatite.

Table 1. Roughness parameters of the analysed implants.

\begin{tabular}{lccc}
\hline Specimen & $\mathrm{Ra}(\mu \mathrm{m})$ & $\mathrm{Rq}(\mu \mathrm{m})$ & $\mathrm{Rz}(\mu \mathrm{m})$ \\
\hline As- machined & $1.8 \pm 0.9$ & $2.0 \pm 1.0$ & $22 \pm 5$ \\
$\mathrm{Al}_{2} \mathrm{O}_{3}$ blasted & $3.4 \pm 0.2$ & $8.9 \pm 0.1$ & $151 \pm 3$ \\
Ti plasma-sprayed & $5.0 \pm 1.0$ & $6.0 \pm 1.0$ & $32 \pm 1$ \\
HA coated & $5.0 \pm 0.6$ & $6.5 \pm 0.7$ & $34 \pm 3$ \\
\hline
\end{tabular}

$\mathrm{R}_{\mathrm{a}}=$ the arithmetic average; $\mathrm{R}_{\mathrm{q}}=$ the root-mean-square; $\mathrm{R}_{\mathrm{Z}}=$ the average value of the absolute heights of the five highest peaks and the depths of the five deepest valleys.

The topographic maps, Figs. 4a to 4d, showed, qualitatively, the difference in roughness between the four surfaces. When comparing the maps of the different specimens, it should be noted that a different scale was used for the machined specimen. Laser scanning confocal microscopy can be an useful tool for roughness measurements but this quantification depends on pattern calibration, so this qualitative analysis was complemented by the measurement of the roughness parameters by profilometry. The roughness parameters of the analysed surfaces are shown in Table 1. The titanium plasma-sprayed sample and the electyrolytically coated specimen exhibit $R_{a}$ equal to $5.0 \mu \mathrm{m}$, a higher value than the measured one for the other two surface conditions. The similarity in roughness be-

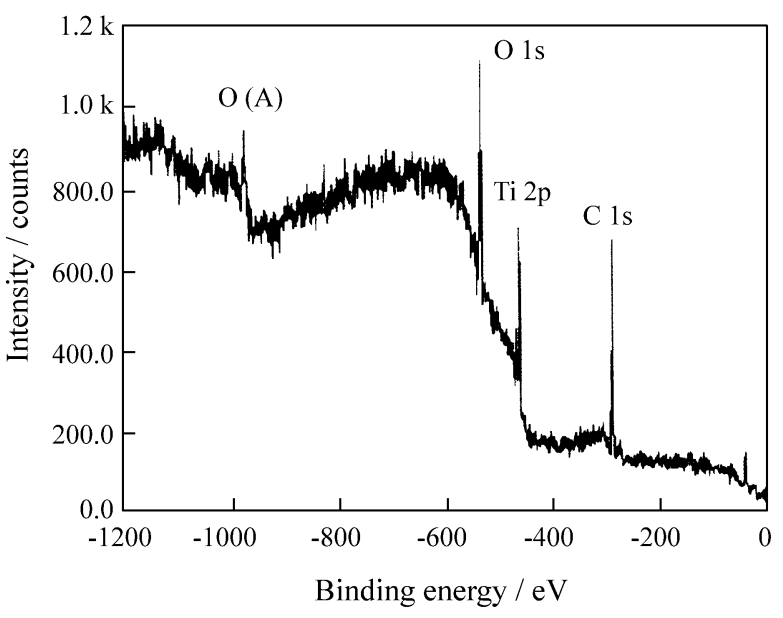

Figure 5. XPS spectrum for the as-machined specimen.

tween the plasma-sprayed and the electrolytically coated specimens was also observed for the other two roughness parameters $\left(R_{\mathrm{q}}\right.$ and $\left.\mathrm{R}_{\mathrm{z}}\right)$. The alumina blasted specimen showed the highest values of $R_{q}$ and $R_{z}$, indicating a very irregular surface. The arithmetic average roughness $\left(R_{a}\right)$ for the electrolytically coated implant is in the same range of values reported in the literature for hydroxyapatite coated by a plasma-spraying process, according to Wong et al. ${ }^{19}$. Moreover, as mentioned before, the implant that was elec- 

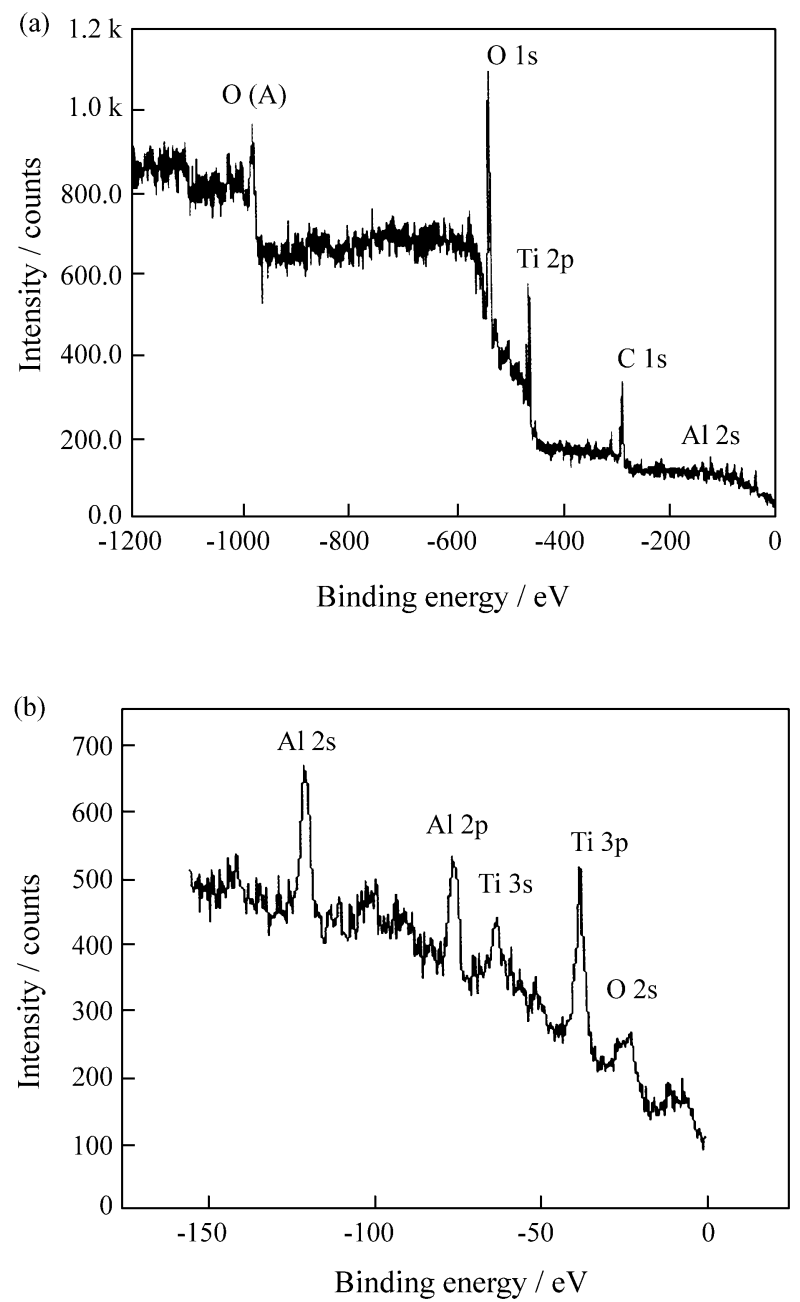

Figure 6. XPS spectra for $\mathrm{Al}_{2} \mathrm{O}_{3}$-blasted sample. a) general view; b) detail near aluminium peak.

trolytically coated with hydroxyapatite showed crystallites in the scale of nanometres. This feature suggests a large increase in surface area compared to the other specimens that had features in the scale of microns. As the profilometry measured roughness at a micrometric scale, results from Table 1 could not describe the topography of all samples in a nonometric scale.

XPS analysis revealed the characteristic adsorption of carbon on the four analysed surfaces. This carbon adsorption occurs on every surface that is exposed to the atmosphere and is detected by the XPS technique. As might be expected, the as-machined implant showed no traces of contaminants, Fig. 5. The $\mathrm{Al}_{2} \mathrm{O}_{3}$ blasted specimen spectrum (Fig. 6) showed contamination with aluminium, also identified by SEM, which was associated to the alumina particles from the blasting process. Analysis of the titanium plasma-sprayed specimen indicated some contamination with aluminium and zinc, Fig. 7b. This can be associated to
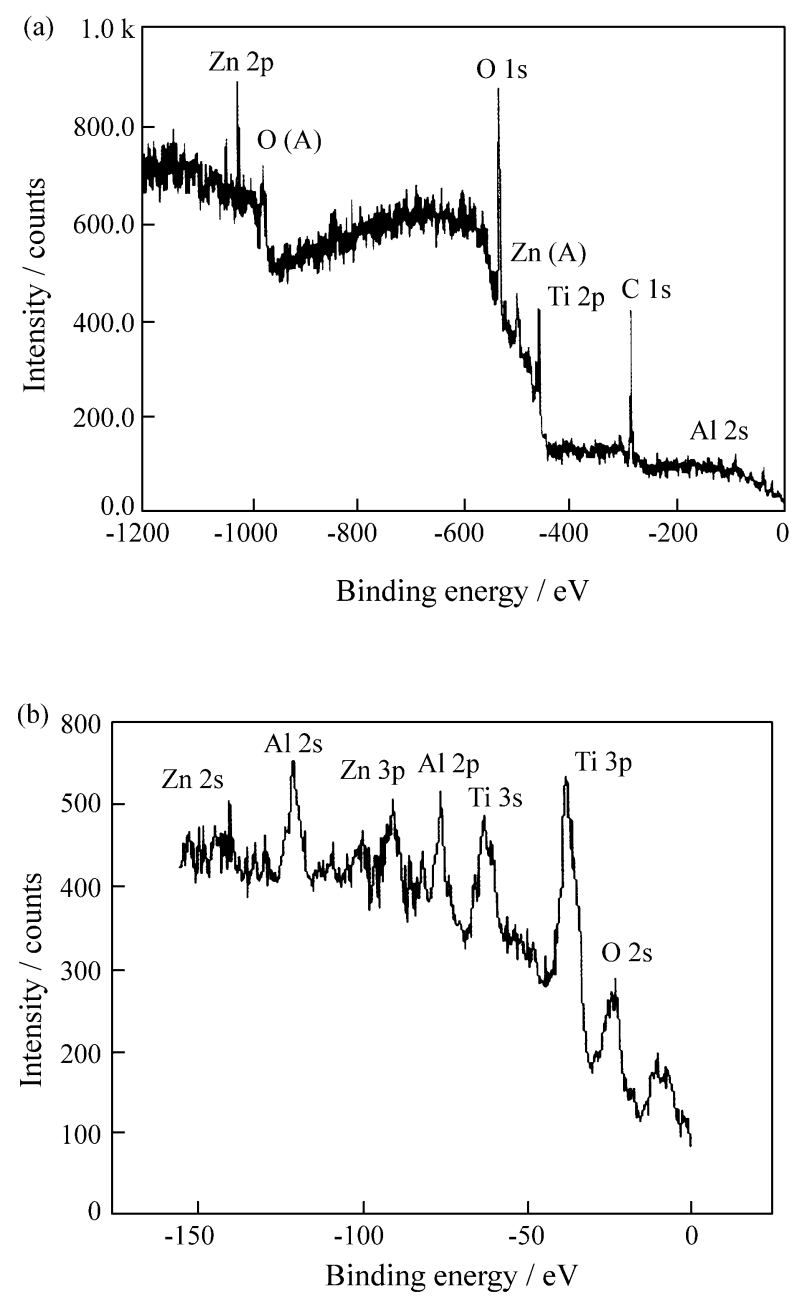

Figure 7. XPS spectra for sample plasma-sprayed with titanium. a) general view; b) details near $\mathrm{Al}$ peak.

the blasting process prior to the plasma-spraying, as this specimen was first blasted with alumina particles to create a rough surface. It is thought that the detergents used in the cleaning procedure were the most probable origin of the zinc contamination ${ }^{20}$. The hydroxyapatite coated specimen showed traces of sodium, remaining from the coating process, as indicated in the spectrum shown in Fig. 8d. The measured $\mathrm{Ca} / \mathrm{P}$ ratio varies from 1.58 to 1.73 . Considering a possible variation of $10 \%$ when quantification is done using XPS spectra, this range could correspond to stoichiometric hydroxyapatite $(\mathrm{Ca} / \mathrm{P}=1.67)$ or calcium-deficient hydroxyapatite $(\mathrm{Ca} / \mathrm{P}=1.50)$. With infrared spectroscopy using the diffuse reflectance mode (DR-IR) small amounts of carbonate-apatite were identified ${ }^{21}$.

\section{Conclusions}

The techniques utilised in this study were effective in the characterisation of the morphology, surface quality 

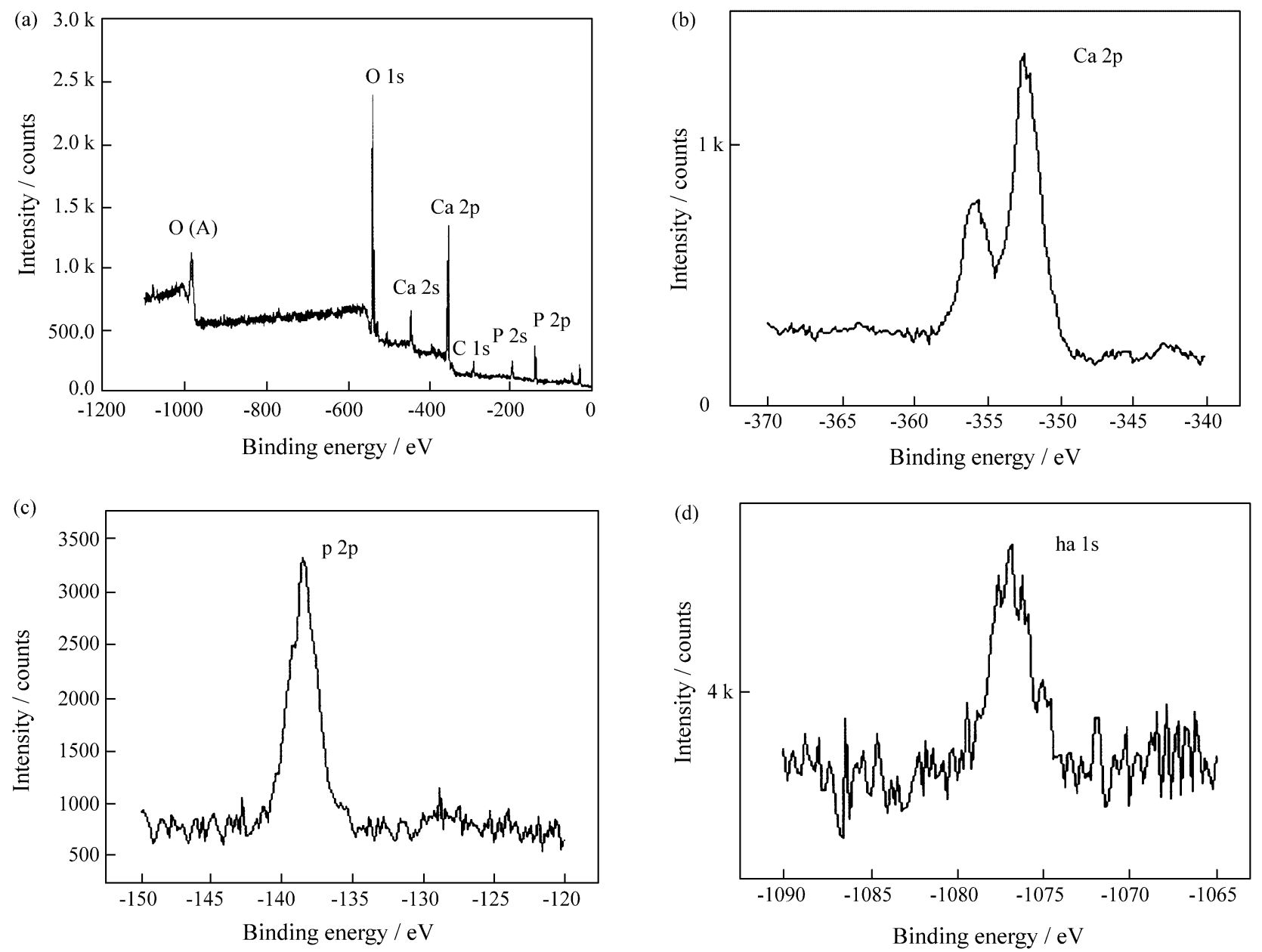

Figure 8. XPS spectra for sample electrolytically-coated with hydroxyapatite. a) general view; b) details near calcium peak; c) details near phosphorus peak; d)details near sodium peak.

and chemical purity of the analysed surfaces. As might be expected,theas-machinedimplantpresented thesmoothest surface. The implant that was electrolytically coated with hydroxyapatite showed roughness similar to data obtained for titanium plasma-sprayed specimen and similar to the data reported in the literature for commercial implants coated with hydroxyapatite by the plasma-spraying process. Moreover the nanometric crystallites identified in the sample electrolytically coated with hydroxyapatite act to increase the surface area, although the correlation of this event with cell attachment remains unknown.

SEM/EDS is, as predicted, a good tool for topographic visualisation and/or particle identification while contamination from the different surface treatments was detected by XPS analysis. These findings suggest that careful consideration must be given while manufacturing, cleaning and sterilising the implants since the nature of the surface can influence bone-bonding events.

\section{Acknowledgements}

The authors would like to acknowledge the support of CAPES, CNPq, FAPERJ and FUJB for the Brazilian government grant and the EPSRC for funding of the core programme of the IRC in Biomedical Materials. They would also like to thank Conexão Sistemas de Prótese S.A., for supplying the implants. The XPS spectra were obtained in the NUCAT Lab. at PEQ/COPPE/UFRJ.

\section{References}

1. Kasemo, B.; Lausmaa, J. Tissue-Integrated Prostheses - Osseointegration in Clinical Dentistry. Quintessence Publishing Co., Inc., Chicago, p. 99, 1985.

2. Muster, D.; Demri, B.; Hage Ali, M. Enclyc. Handbook of Biomaterials and Bioengineering, part A, v. 2, p. 785-812, 1995.

3. Wennerberg, A.; Albrektsson, T.; Ulrich, H.; Krol, J.J. J. Biom. Eng., v.14, p. 412-418, 1992. 
4. Siedlecki, C.A.; Marchant, R.E. Biomaterials, v. 19, p. 441-454, 1998.

5. Oshida, Y.; Sachdeva, R.; Miyazaki, S.; Daly, J. J. Mater. Sci.: Mater. in Medicine, v. 4, p. 443-447, 1993.

6. Wennerberg, A.; Albrektsson, T.; Andersson, B. J. Mater. Sci.: Mater. in Medicine, v. 6, p. 302-309, 1995.

7. Ishizawa, H.; Fujino, M.; Ogino, M. Bioceramics, v. 9, Pergamon/Elsevier, UK, p. 329-332, 1996.

8. Keller, J.C.; Draughon, R.A.; Wightman, J.P.; Dougherty, W.J.; Meletiou, S.D. J. Oral \& Maxillofacial Impl, v. 5, p. 360-367, 1990.

9. Kieswetter, K.; Shwartz, Z.; Hummert, T.W.; Cochran, D.L.; Simpson, J.; Dean, D.D.; Boyan, B.D. J. of Biom. Mater. Res., v. 32, p. 55-63, 1996.

10. Boyan, B.D.; Hummert, T.W.; Dean, D.D.; Schwartz, Z. Biomaterials, v. 17, p. 137-146, 1996.

11. Suzuki, K.; Aoki, K.; Ohya, K. Bone, v. 21, p. 507514, 1997.

12. Wennerberg, A.; Ektessabi, A.; Albrektsson, T.; Johansson, C.; Anderson, B. J. Oral \& Maxillofacial Impl, v. 12, p. 486-494, 1997.
13. Wong, M.; Eulenberger, J.; Schenk, R.; Hunziker, E. J. of Biom. Mater. Res., v. 29, p. 1567-1575, 1995.

14. Da Silva, M.H.P.; Soares, G.A.; Elias, C.N.; Gibson, I.R.; Best, S.M.; Bonfield, W. Bioceramics, v. 11, p. 223-226, 1998.

15. Asaoka, N.; Best, S.; Bonfield, W. Bioceramics, v. 10, p. 447-450, 1998.

16. Lacefield, W.R. Implant Dentistry, v. 7, n. 4, p. 315321, 1998.

17. Willmann, G. Bioceramics, v. 10, p. 353-356, 1997.

18. De Groot, K.; Wolke, J.C.K.; Jansen, J.A. Journal of Oral Implantology, p. 232-234, 1994.

19. Wong, M.; Eulenberger, J.; Schenk, R.; Hunziker, E. Journal of Biom. Mater. Res., v. 29, p. 1567-1575, 1995.

20.Prado da Silva, M.H. Ph.D. Dissertation, COPPE/UFRJ, 166 p., 1999.

21. Oliveira, J.F.; Sena, L.A.; Prado da Silva, M.H.; Soares, G.A.; Rossi, A.M. Bioceramics, to be published, 2000. 